\title{
Study on the Behavior of Peled (Coregonus Peled) Around a Set Net by Ultrasonic Biotelemetry System in a Plateau Lake, China
}

Jing Liu

College of Marine Sci-Tech and Environment, Dalian Ocean University, China

Keiichi Uchida

Tokyo University of Marine Science and Technology (TUMSAT), Japan

Leiming Yin

College of Marine Sci-Tech and Environment, Dalian Ocean University, China

Yong Tang

College of Marine Sci-Tech and Environment, Dalian Ocean University, China, tang@dlou.edu.cn

Yoshinori Miyamoto

Tokyo University of Marine Science and Technology (TUMSAT), Japan

See next page for additional authors

Follow this and additional works at: https://jmstt.ntou.edu.tw/journal

Part of the Fresh Water Studies Commons, Marine Biology Commons, Ocean Engineering Commons, Oceanography Commons, and the Other Oceanography and Atmospheric Sciences and Meteorology Commons

\section{Recommended Citation}

Liu, Jing; Uchida, Keiichi; Yin, Leiming; Tang, Yong; Miyamoto, Yoshinori; and Xing, Binbin (2021) "Study on the Behavior of Peled (Coregonus Peled) Around a Set Net by Ultrasonic Biotelemetry System in a Plateau Lake, China," Journal of Marine Science and Technology: Vol. 29: Iss. 2, Article 7.

DOI: $10.51400 / 2709-6998.1079$

Available at: https://jmstt.ntou.edu.tw/journal/vol29/iss2/7

This Research Article is brought to you for free and open access by Journal of Marine Science and Technology. It has been accepted for inclusion in Journal of Marine Science and Technology by an authorized editor of Journal of Marine Science and Technology. 
Study on the Behavior of Peled (Coregonus Peled) Around a Set Net by Ultrasonic Biotelemetry System in a Plateau Lake, China

\section{Authors}

Jing Liu, Keiichi Uchida, Leiming Yin, Yong Tang, Yoshinori Miyamoto, and Binbin Xing 


\title{
Study on the Behavior of Peled (Coregonus Peled) Around a Set Net by Ultrasonic Biotelemetry System in a Plateau Lake, China
}

\author{
Jing Liu ${ }^{a, b}$, Keiichi Uchida ${ }^{b}$, Leiming Yin ${ }^{a}$, Yong Tang ${ }^{a, *}$, \\ Yoshinori Miyamoto ${ }^{b}$, Binbin Xing ${ }^{a}$ \\ ${ }^{a}$ College of Marine Sci-Tech and Environment, Dalian Ocean University, Dalian, Liaoning, 116023, China \\ b Tokyo University of Marine Science and Technology (TUMSAT), Tokyo, 108-8477, Japan
}

\begin{abstract}
Sayram Lake is a plateau cold-water lake located in northwestern China. Peled (Coregonus peled) was introduced to Sayram Lake from Russia in 1998. The behavior characteristics of peled in Sayram Lake are important for fishery resource proliferation, effective fishing, and sustainable development. In this study, we used an ultrasonic biotelemetry system to track the fish around a large-scale set net in Sayram Lake. The purpose of this study is to study the behavior characteristics of the peled and to provide suggestions for the improvement of the set net. The results showed that the fish released in the playground of the set net rarely swam into the middle bag net. Six of the 11 experimental fish wandered around the playground of the set net after being released and finally escaped from the set net within $17 \mathrm{~h}$. Finally, three of the released fish swam into the right-hand bag net of the set net. The fish that escaped from the set net tended to swim clockwise along Sayram Lake and tended to swim toward shallow water. The main activity depth of the fish was $0-15 \mathrm{~m}$. The swimming speed of the fish in the lake ranges from 0.26 to 2.04 body length (BL) per second. This information is of great significance for the design and site selection of large-scale set nets.
\end{abstract}

Keywords: Ultrasonic biotelemetry, Tracking, Behavior characteristics, Swimming speed, Set net

\section{Introduction}

$S$ ayram Lake is located in Western China's North Tianshan mountains (E $\left.81^{\circ} 05^{\prime}-81^{\circ} 15^{\prime} 、 \mathrm{~N} 44^{\circ} 30^{\prime}-44^{\circ} 42^{\prime}\right)$, which has an altitude of $2073 \mathrm{~m}$, a circumference of $90 \mathrm{~km}$, an area of $458 \mathrm{~km}^{2}$, and a maximum depth of $102 \mathrm{~m}$. This lake is largely irregular in the shape of a diamond and embedded in the mountain basin. The annual average surface temperature of this lake is about $7^{\circ} \mathrm{C}$, and the lake has an ice period from January to April. The lake basin formed in the Pliocene of Tertiary Period or early Quaternary Period, which bears the whole quaternary glaciation [25]. The geographical location is shown in Fig. 1. In the 1970s, Chinese fishery researchers tried to introduce Gymnodiptychus dybowskii, Leuciscus merzbacheri, etc. into the lake, but all ended in failure. In 1998, peled and arctic cisco (Coregonus autumnalis) were introduced to the lake from Russia, and now peled has become the main economic species in the lake [7]. The annual output is about $300 \mathrm{t}$. Peled in Sayram Lake cannot breed naturally and thus need to be bred in a breeding factory and then transferred to the lake. The breeding work for peled is difficult, so the juvenile peled is very precious; therefore, it is very important to protect the juvenile fish. 


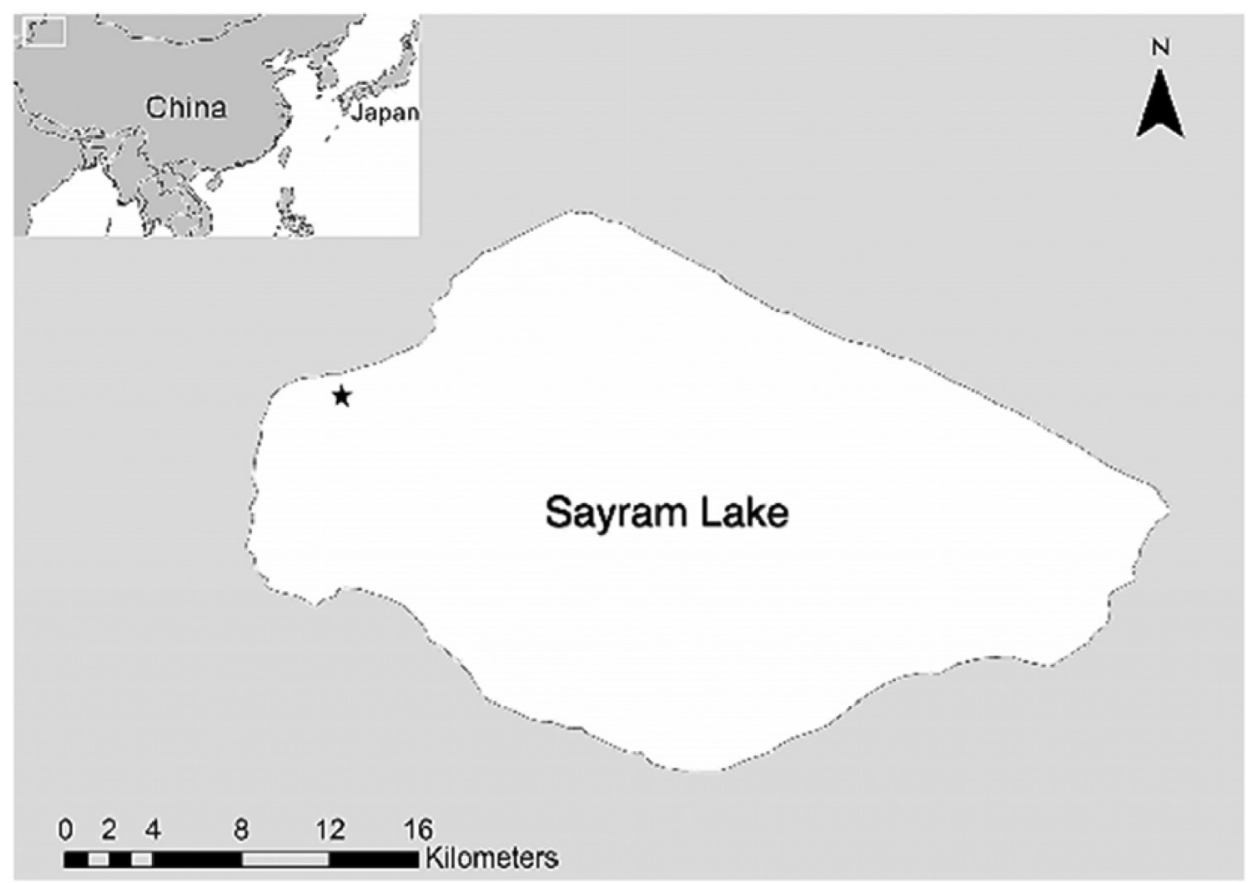

Fig. 1. Location of Sayram Lake and a large-scale set net (marked with a black star) in this study.

However, the traditional fishing gear, the gill net and the small set net, have poor selectivity for juvenile fish, so juvenile fish are easily damaged by this fishing gear. A total of 28 small set nets were distributed along the western coast of Sayram Lake. When the production of small set nets was insufficient, less than 10 gill nets would be randomly set along the whole coast of Sayram Lake. Gill nets and small set nets also have other disadvantages: they have high fuel consumption, they are easy to break and lose, and they have a bad influence on the environment. The lake is not only a fishery production lake but also a national scenic spot in China, so environmental impacts need to be considered while fishery production is being carried out.

In order to solve the above problems, in 2017, researchers of the Dalian Ocean University and Sayram fishery company developed and designed a large-scale set net by combining the experience of using a small set net in the lake to replace the previous fishing gear-the gill net and small set net. The fish behavior information plays an important role in designing and improving such a large-scale set net. However, since most previous research on peled focused on breeding, growth, and biology, the research on its behavior has not been reported $[8,23]$.
The ultrasonic biotelemetry system has been used in tracking a variety of aquatic animals ranging from 6-g salmon smolts to 150 -t whales in oceans, rivers, and lakes since its first application in 1956; this system has played an important role in the study of fish behavior and ecological protection of fishery resources [4]. It is currently the most direct and effective method to study the migration pattern, spawning habitat, distribution characteristics, homing ability, home range size, and so on of fish in open waters $[1,3,11,18,21]$. Moreover, by observing the fish's response characteristics to fishing gear, it is also possible to provide scientific guidance on the improvement of fishing gear design and site selection $[12,13,24]$. Compared to rivers and oceans, it is easier in lakes to study the behavioral characteristics of fish using ultrasonic biotelemetry technology, because lakes are closed waters. In recent years, the Great Lakes Acoustic Telemetry Observation System (GLATOS) has done research on the behavior of fish in some lakes of North America using ultrasonic biotelemetry technology. They have provided useful information for lake ecological management and fishery managers $[9,10,18]$. However, at present, there is no research on fish behavior using ultrasonic biotelemetry technology in cold water lakes on the plateau. In theory, it is easier to conduct biotelemetry experiment on a plateau lake because of less environment noise, and the target species of this study is peled, which was introduced from Russia. It 
is important to study the behavior of such an alien species in a plateau cold water environment.

Therefore, in this study, the ultrasonic biotelemetry system was used to track the peled and obtain relevant behavioral information, so as to test the fishing effect of the new set net and provide a scientific basis for site selection and fishing gear improvement. We can also gradually grasp the migration and related behavior characteristics of the peled in Sayram Lake and lay a foundation for the future behavior research of the fish on seasonal tracking and on the whole lake scale.

\section{Material and method}

\subsection{Long base line tracking in a large-scale set net}

During June 22, 2018 to June 29, 2018, the Long Base Line (LBL) ultrasonic biotelemetry system was used to carry out the tracking experiment on the peled in a large-scale set net, marked with a black star in Fig. 1. The structure of the set net is shown in Fig. 2; it consists of a lead net, a palyground, 2 middle bag net, and 2 bag net. The average water depth of the playground area is $32.8 \mathrm{~m}$. The actual shape and size of the set net are measured using a handheld GPS (GARMIN-621sc). A pretest was conducted to detect the effective receiving distance between the receiver and the ultrasonic transmitter in the lake before setting the receiver array, and an effective receiving distance of about $300 \mathrm{~m}$ was confirmed. The average distance between receivers was $184 \mathrm{~m}$. Ten stationary receivers (AQRM-1000, Aquasond Inc., Japan) were used to form the LBL biotelemetry array. Receiver 1 to Receiver 8 was mainly used to collect the signals from the test fish in the set net. Receiver 9 and Receiver 10 were mainly used to observe the approximate location information of the experimental fish after escaping from the set net, and Receiver 9 and Receiver 10 were respectively set on both sides of the lead net. The receivers were fixed $2 \mathrm{~m}$ below the surface of the water around the set net through float and sink. The position of each receiver was recorded by the handheld GPS (GARMIN-621sc), and the black triangle in Fig. 2 shows these positions. In order to calibrate the clock difference between each receiver, two synchronous ultrasonic transmitters were suspended $1 \mathrm{~m}$ underwater near receivers 4 and 8 , respectively. $[1,20]$. The ultrasonic transmitters used in this study were Goldcode Pinger (AQPX-1030P, $62.5 \mathrm{kHz}$, Aquasond Inc., Japan). This system can identify up to 32 ultrasonic transmitters at the same time. The ultrasonic transmitter was implanted in the abdomen of the experimental fish by surgery. The depth change of the experimental fish was obtained by the depth sensor inside the ultrasonic transmitter. According to the time difference between the ultrasonic signals propagating from the experimental fish and at least three receivers, combining the depth data obtained by the depth sensor, the hyperbolic positioning method was used to determine the position of the experimental fish, which is also called LBL tracking [20]. A total of 11

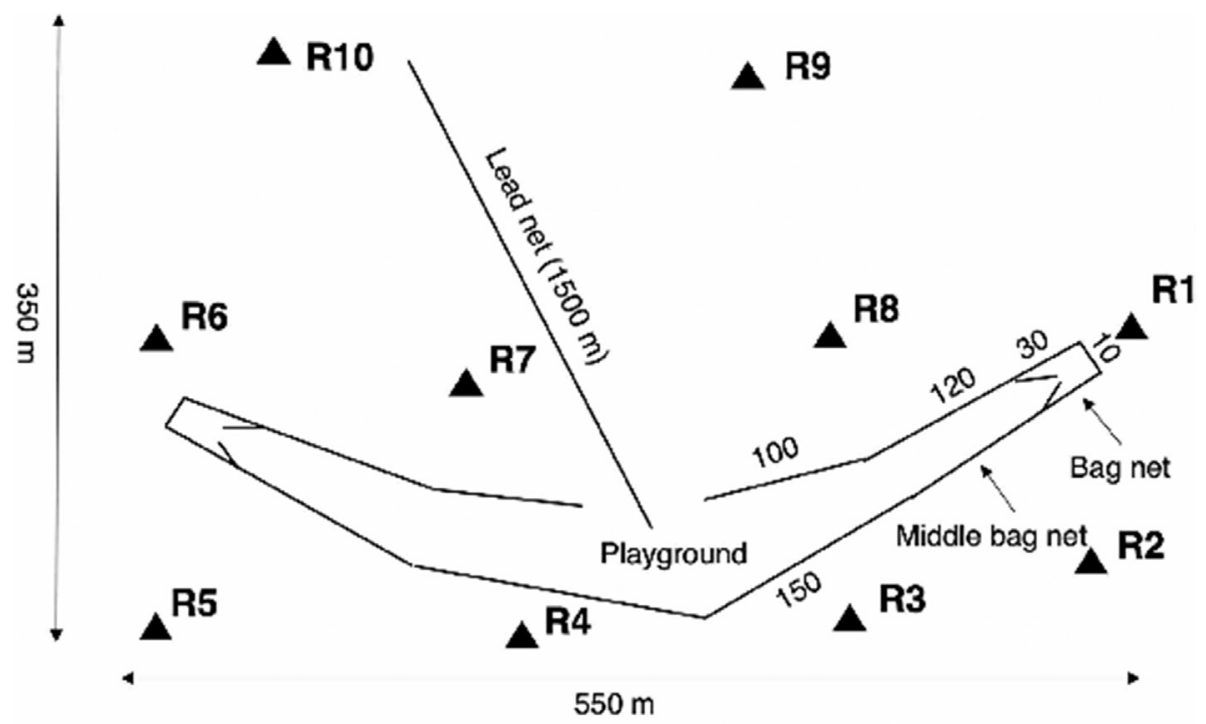

Mooring receiver

Fig. 2. Diagram of the set net used in Sayram Lake. The black triangles represent the positions of receivers, and the numbers represent the lengths of each part of the set net (in meters). 
experimental fish were released into the playground area of the set net, and the release experiment was carried out in three stages. The first time was 15:30 on June 23, 2018; two peleds were released, and the setting interval of the ultrasonic transmitter was $2 \mathrm{~s}$. The second time was 12:10 on June 24, 2018; a total of 5 peleds were released with an ultrasonic signal interval of $1 \mathrm{~s}$. The third time was June 27, 2018, 16:12; a total of 4 peleds were released, with an ultrasonic signal interval of $1 \mathrm{~s}$.

\subsection{Inferring the general position of the experimental fish based on the number of signals received by each receiver}

Because of the changeable weather condition in the plateau lake, the receivers sometimes could not receive enough effective signals from the ultrasonic transmitter, and because of the influence of multiple reflection waves from the lake bottom, the lake surface, and the fishing net, it was sometimes difficult to accurately calculate the position of the experimental fish. As a result, the tracking results calculated by the hyperbolic positioning method are incomplete. Therefore, in this study, we used another method to analyze the position information of the experimental fish as a supplement when it was difficult to track using the LBL method. Since the effective receiving range of the receiver is limited, in a certain period of time, if a receiver received significantly more signals than other receivers, we determined that the experimental fish mainly moved around this receiver during this period. In the same way, we also used this method to determine when the experimental fish eventually escaped from the receiver array area. This method is based on the number of received signals used for locating, so in this paper we referred to this method as NRS.

\subsection{Swimming speed measurement in situ}

On the base of the LBL biotelemetry system, the swimming speed of the peled in the lake was calculated. The following steps were taken: (1) According to the scattered plot of the hyperbolic positioning result, the track segments of the swimming path, which was approximately a straight line, were selected. (2) The line segments located inside the receiver array were determined from the track segments obtained in Step 1, because the position measurement error in the array was small. (3) According to the track line segments obtained in Step 2 , the coordinates of the first and last points of the track segments and the corresponding time were recorded, respectively. (4) The average swimming speed was obtained by dividing the distance difference of each set of coordinates in Step 3 by each set of time differences. The swimming speed was calculated using the head and tail coordinates of the track lines rather than the adjacent coordinates because there were errors at each measurement point, and the overall error can be effectively reduced by using the first and last coordinates of the track of the line segment. (5) The multiple swimming speeds of each fish were calculated, and an average value was determined.

\section{Results}

\subsection{Vertical movement of the peled}

Eleven experimental fish were recorded as C1-C11 according to the release time order. Because the effective receiving signal range of the receiver was limited, and there was noise interference, the number of signals from each experimental fish received by different receivers in each time period was different. Therefore, when processing the depth data of the experimental fish, we separately calculated the depth of each experimental fish and processed it at hourly intervals. Since different receivers received different numbers of signals in the same hour, we selected the receiver with the largest number of signals for depth calculation. According to the depth calculation result, it was found that the swimming depth of the peled was always between 0 and $15 \mathrm{~m}$. Occasionally, the peled dove to $20 \mathrm{~m}$, but soon returned to the shallow water. There was no significant difference in swimming patterns between day and night according to the depth diagrams of C3, C4, and C6. Fig. 3 shows four representative swimming depth diagrams within $12 \mathrm{~h}$ after the peled were released. The triangle marks in the figure indicate that the experimental fish left the waters near the set net temporarily or permanently because no receiver could receive an effective depth signal at that time interval. As can be seen in Fig. 3-C1 and Fig. 3-C3, there is more than 1 triangle mark in the depth diagrams, indicating that the test fish escaped from the set net area several times and then returned to the set net area again.

\subsection{Position tracking of the experimental fish in a large-scale set net}

As mentioned above, due to environmental conditions and other factors, the data amount of each experimental fish recovered from the receiver was 


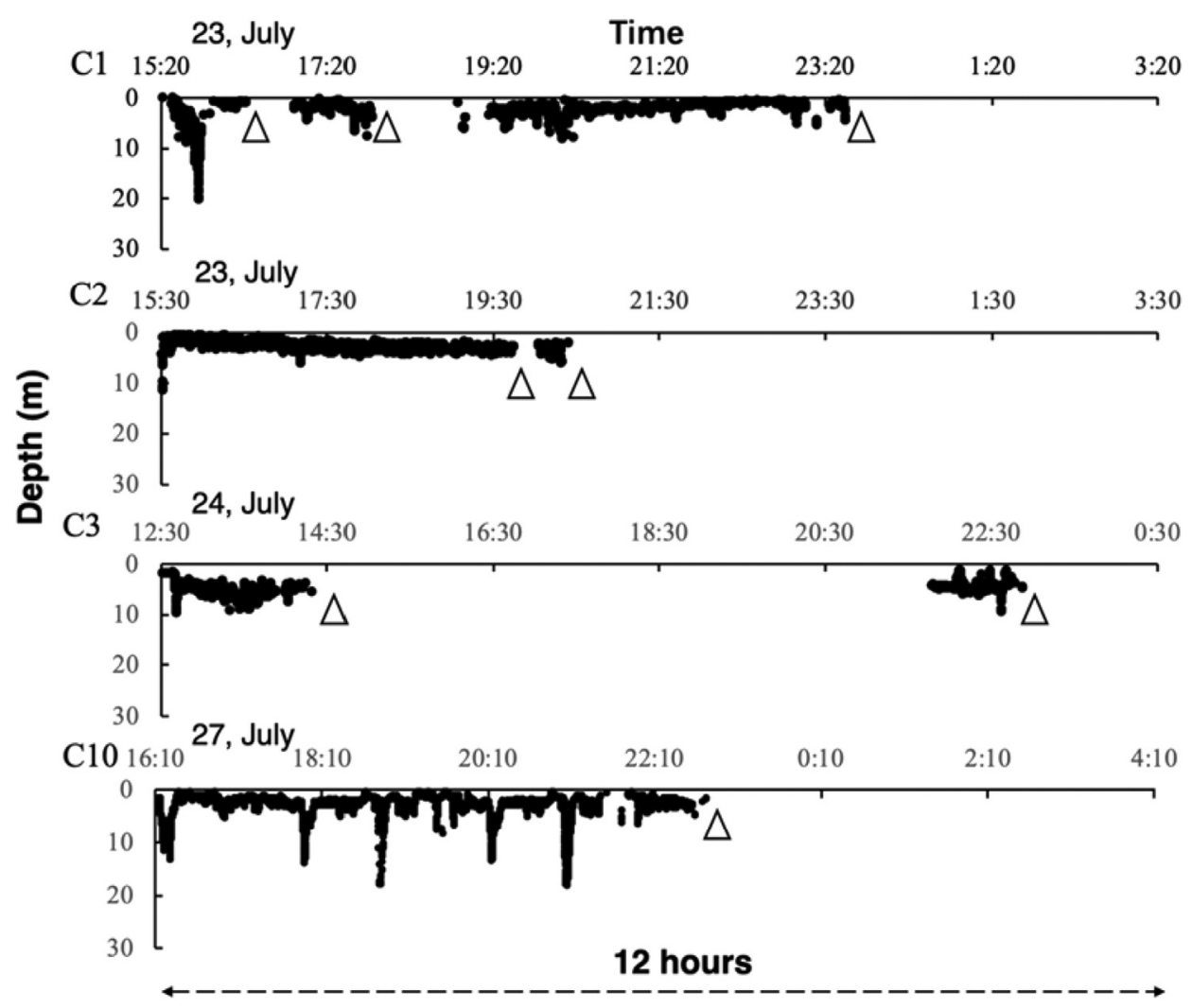

Fig. 3. Example images of the vertical movement of the peled within $12 \mathrm{~h}$ after being released. The triangle marks in the figure indicate that the experimental fish left the waters near the set net temporarily or permanently.

quite different. Therefore, we selected four experimental fish with sufficient effective data for LBL hyperbolic positioning analysis. The tracking result is shown in Fig. 4. For the remaining seven fish, the NRS tracking method is used to determine the time and approximate location information when the experimental fish escaped from the receiver array.

Figure 4 shows the results of the location-tracing of four experimental fish. The circle in Fig. 4 represents the starting point of the tracks, the square represents the position of the test fish before finally disappearing, the arrow represents the direction in which the fish were swimming, and the numbers represents the order in which the test fish appear. We can see in Fig. 4 that, after being released at 15:30, C1 moved toward the middle of the playground and escaped from the entrance of the playground about $8 \mathrm{~min}$ later. $\mathrm{C} 1$ then suddenly appeared at the north of the lead net and moved toward the playground along the lead net, after which $\mathrm{C} 1$ appeared on the right side of the set net again after about $4.5 \mathrm{~h}$. Finally, the signals were gradually lost because $\mathrm{C} 1$ was too far away from the receiver. C2 was released at 15:30. After being released, C2 started to move back and forth five times in the east and west direction of the playground of the set net. After $3.3 \mathrm{~h}, \mathrm{C} 2$ escaped from the set net and fled northwestward along the lead net. C3 was released at 12:10. C3 and C2 had a similar movement pattern, but $\mathrm{C} 3$ stayed in the playground for less time than $\mathrm{C} 2$ and escaped from the set net $1.7 \mathrm{~h}$ after being released. C10 was released at 16:12. As can be seen from Fig. 4-C10, C10 escaped through the net wall of the set net $3 \mathrm{~h}$ after being released, and then through the net wall of the lead net again. The four test fish escaped firstly after staying in the set net for less than $3.3 \mathrm{~h}$, indicating that the design of the playground entrance could not effectively prevent the fish from escaping. The four test fish never entered the middle bag net before escaping, indicating that the middle bag net channel could not effectively lure the test fish into the bag net.

The bar graphs of Fig. 5 show the total number of signals received by all receivers within each hour after the test fish was released. It can be clearly seen in the bar graphs that the test fish C1, C2, C3, C5, C10, and C11 lost their signals from the 9th, 6th, 11th, 9th, 18th, and 17th hour, respectively, which means that the test fish finally escaped from the set 

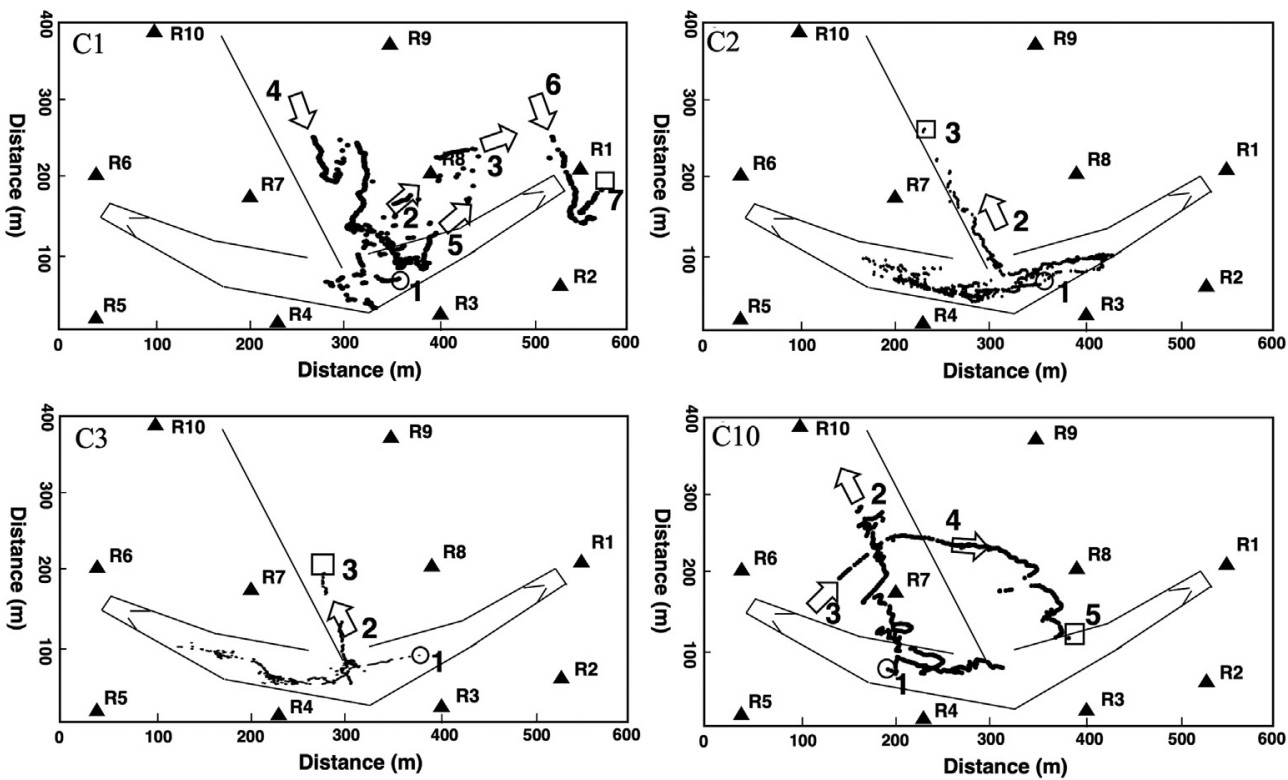

Fig. 4. Example images of the fish that escaped from the set net. Circles represent the starting point of the tracks, the squares represent the position of the fish before finally disappearing, the arrows represent the direction in which the fish were swimming, and the numbers represent the order in which the fish appear.

net area. According to the depth results, the depth of C7 was stationary at about $23 \mathrm{~m} 1.7 \mathrm{~h}$ after being released, which indicated that the transmitter was likely to fall off from the fish. C9 is thought to have been suspended on the net because its depth remained constant at $2 \mathrm{~m}$, and its horizontal position also remains roughly unchanged. The bar graphs also show that the $\mathrm{C} 7$ and $\mathrm{C} 9$ transmitters remained in the set net because the received signals at each hour were stable. Based on the depth change and the number of received signals, we believe that $\mathrm{C} 4$, C6, and C8 did not escape from the set net area.

According to the results of LBL analysis and the change in NRS, the time taken by the test fish to
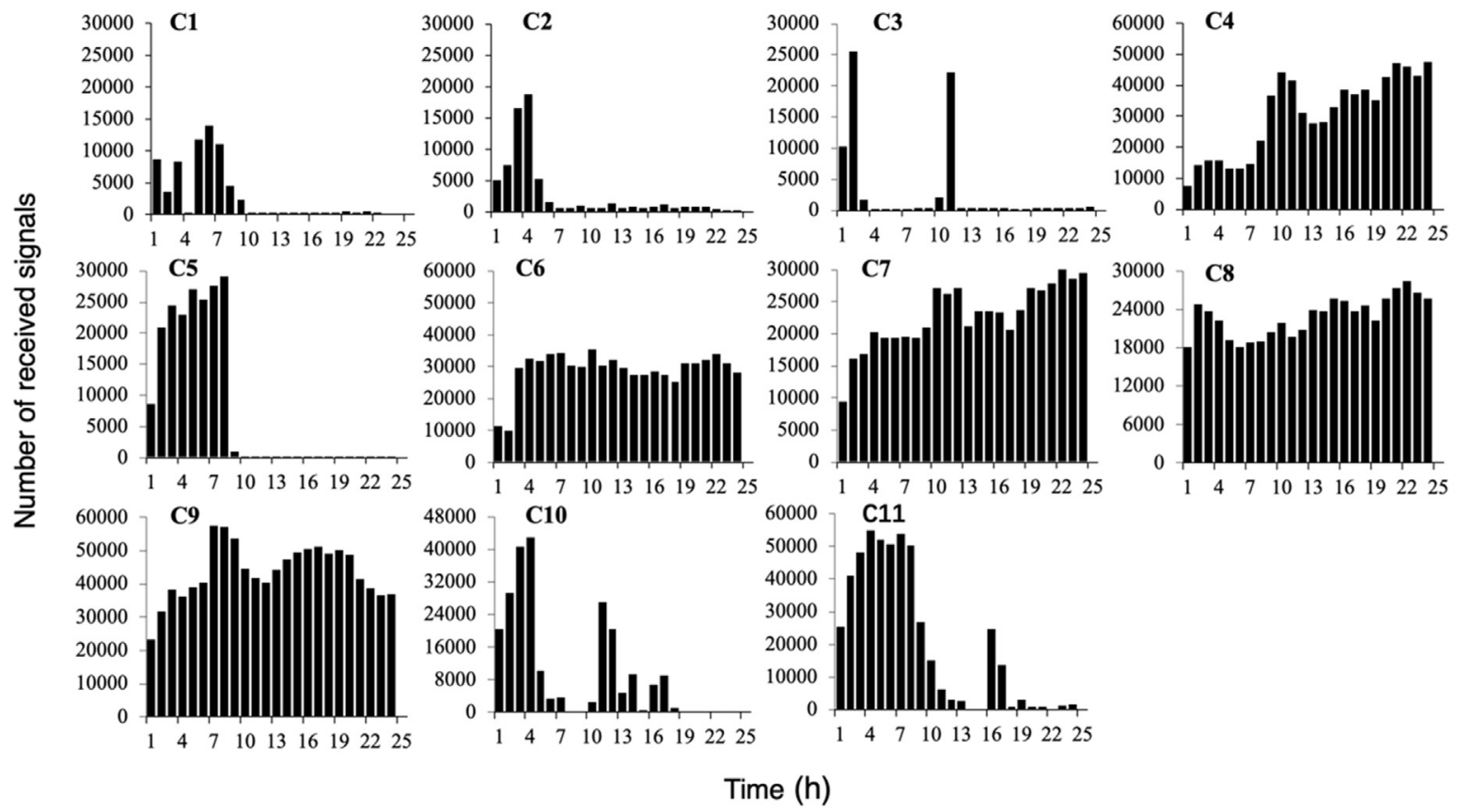

Fig. 5. The total number of signals received by all receivers within each hour over $24 \mathrm{~h}$ after the test fish were released. It can be clearly seen in the bar graphs that the test fish C1, C2, C3, C5, C10, and C11 escaped from the set net area because the receivers finally lost the signal. 
Table 1. Residence time before escaping from the set net of 11 experimental fish.

\begin{tabular}{lllllll}
\hline Fish code & Signal interval $(\mathrm{s})$ & Body length $(\mathrm{cm})$ & Release time & Escaped or not in $24 \mathrm{~h}$ & Judgement method & Residence time $(\mathrm{h})$ \\
\hline C1 & 2 & - & $15: 306 / 23$ & Yes & LBL & 9 \\
C2 & 2 & - & $15: 306 / 23$ & Yes & LBL & 6 \\
C3 & 1 & 34 & $12: 106 / 24$ & Yes & LBL & NRS \\
C4 & 1 & 35 & $12: 106 / 24$ & No & NRS & / \\
C5 & 1 & 32 & $12: 106 / 24$ & Yes & NRS & $/$ \\
C6 & 1 & 32 & $12: 106 / 24$ & No & $/$ & $/$ \\
C7 & 1 & 33 & $12: 106 / 24$ & $/$ & NRS & $/$ \\
C8 & 1 & 33 & $16: 126 / 27$ & No & I & 1 \\
C9 & 1 & 34 & $16: 126 / 27$ & $/$ & LBL & 18 \\
C10 & 1 & 38 & $16: 126 / 27$ & Yes & NRS & 17 \\
C11 & 1 & - & $16: 126 / 27$ & Yes & & \\
\hline
\end{tabular}

escape from the set net area was determined, and according to the number of signals from the experimental fish received by each receiver within an hour before the experimental fish escaped from the receiver array to determine the swimming direction of the experimental fish when they escaped. The experimental fish all moved toward the right side of the set net after they escaped from the set net (facing the lakeshore). The relevant results are shown in Table 1.

Table 1 lists all fish tracking results, except for those of C7 and C9. Six of the nine experimental fish successfully escaped from the set net within $24 \mathrm{~h}$, and according to the result of the LBL and NRS, the experimental fish all moved toward the right side of the set net after they escaped from the set net (facing the lakeshore).

\subsection{Swimming speed of the peled}

The average swimming speed of the four experimental fish in Fig. 4 was calculated according to the operation steps above. The average swimming speed of the four experimental fish in Fig. 4 was 0.87 $\mathrm{BL} / \mathrm{S}, 0.87 \mathrm{BL} / \mathrm{S}, 1.49 \mathrm{BL} / \mathrm{S}$, and $1.03 \mathrm{BL} / \mathrm{S}$, respectively. Fig. 6 shows the frequency of the swimming velocity of the experimental fish in situ. It can be seen in the diagram that the swimming velocity in the open water of the peled was mainly distributed in the range of $0.6-1.0 \mathrm{BL} / \mathrm{S}$. The range of this velocity was assumed to be the normal cruise speed of the peled. The distribution frequency from 1.0BL/S to $2.2 \mathrm{BL} / \mathrm{S}$ decreased gradually, which is believed to be the swimming speed associated with foraging behavior or escape behavior.

\section{Discussion}

\subsection{Swimming speed in situ}

The swimming speed characteristics of fish can reflect behavior of foraging, migration, avoidance, and so on. It is also necessary to consider the swimming speed characteristics of fish in work on the environmental management, aquaculture, and design of fish passageways [17]. Up to now, research on fish swimming speed measurements has been mostly carried out in indoor circulating flumes or small ponds. Two methods to measure the swimming speed of fish in open water area have been reported in previous literature. One is stationary bottom split-beam hydroacoustics [2], and the other is the stereocinematographic (SCG) method [5].

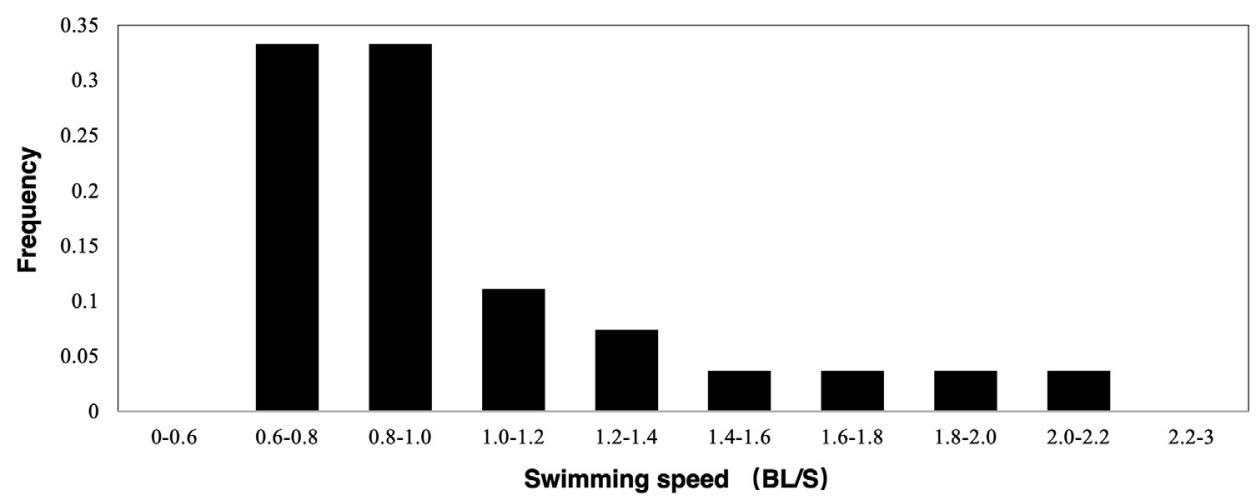

Fig. 6. Swimming speed distribution of the peled measured in this study. 
Distinguishing individual fish is difficult with both of these methods. The detectable distance for swimming speed measurements is short because of the effective beam range of split-beam hydroacoustics and the limitation of the observation range of visual cameras. On the contrary, a biotelemetry receiver array covering hundreds of meters can be easily arranged to measure the swimming speed of fish in open water. A large number of fish can be tagged and detected simultaneously by this method because every acoustic transmitter has a unique code. Although there will be some errors when calculating the swimming speed of fish by using the tracking results of the LBL method [20], several steps have been adopted to reduce these errors. Moreover, according to the research results of Thorstad [22], the swimming speed of adult atlantic salmon (1021-2338 g, total body length 45-59 cm) was not affected when equipped with external or body-implanted biotelemetry transmitters (cylinder, $54 \times 12 \mathrm{~cm}$ ) compared with untagged controls [22]. The average body length of adult peled in this study was about $34 \mathrm{~cm}$, but the transmitter here was smaller. Therefore, we hypothesized that the ultrasonic transmitter used in this study had no significant effect on the swimming speed of the adult peled. We are considering doing further experiments in the future to determine the effect of the implantation of transmitters on the swimming speed of peled.

\subsection{Fish behavior around the set net}

The tracking results in this study showed that, after being released, the peled basically hovered in the playground and then escaped from the entrance of the playground. Rarely did the fish enter the middle bag net. This indicates that the structure of the entrance of the playground and the middle bag net need to be improved. It is suggested that the structure should be improved by adding a return structure or a slope net at the entrance of the playground, as well as a slope net or a funnel net at the entrance of the bag net, because a slope net and a funnel net can effectively prevent the fish from escaping through the entrance of the playground or the bag net [14]. Only two fish swam into the righthand bag net of the set net after $24 \mathrm{~h}$, and all the fish that escaped from the set net tended to swim clockwise along Sayram Lake and tended to swim toward shallow water. Therefore, we should consider whether we should change the location of the set net and whether it is necessary to set two bag nets on both sides of the set net to facilitate improved fishing results based on the behavioral characteristics described above. In addition, it was found that the experimental fish swam through the net of the playground and the lead net. The net mesh size of the playground and the lead net was 11 $\mathrm{cm}$. The adult experimental fish that passed through the net were $38 \mathrm{~cm}$ long and $9.9 \mathrm{~cm}$ high, so these fish can swim through the net. It is important to consider what methods can prevent this phenomenon from occurring, such as reducing the mesh size of the net or using a certain color of net according to the visual characteristics of the target fish [14].

According to the results of this survey, the experimental fish all moved toward the right side (facing the lakeshore) of the set net after they escaped from the set net. Based on this fact, we believe that setting one tuyere for the set net instead of the original two tuyeres will facilitate the escaping fish to enter the net again, and even prevent the fish from escaping from the set net to some extent. It is necessary to demonstrate this conclusion, so as to improve the set net effectively. In addition, in order to obtain the behavioral characteristics of peled in Sayram Lake, we also conducted a preliminary tracking experiment in $25 \mathrm{July}, 2017$. We used the short base line (SBL) method to carry out a tentative tracking experiment in Sayram Lake. We constructed a receiver array on a small boat consisting of four receivers. Pinger was surgically implanted in the abdomen of the fish, and based on the differences between times at which Pinger signals reach different receivers, the position of the Pinger can be judged in real time [16]. The tracking results are as shown in Fig. 7. Although only two fish were tracked in this SBL tracking experiment, combined with the results in the set net, we found that the peled had a tendency to move along the shallow water area of the lake and along the clockwise direction of the lake. This clockwise movement behavior along the lake may be related to the direction of the water current. This information is critical to the location selection of the set net.

Some fish, such as Thunnus obesus and Xiphias gladius, have distinct diurnal depth patterns, and diurnal depth patterns are considered to be correlated with light penetration and water temperature $[6,15,19]$. However, there has not been any relevant research on the vertical movement model behavior of peled. The vertical movement result in this study shows that there is no significant difference in the swimming patterns of peled between day and night. In this experiment, the maximum tracking time was $43 \mathrm{~h}$, because the experimental fish could easily escape from the receiver array, and the tracking time may be too short to observe the diurnal depth patterns. The behavior characteristics of the 

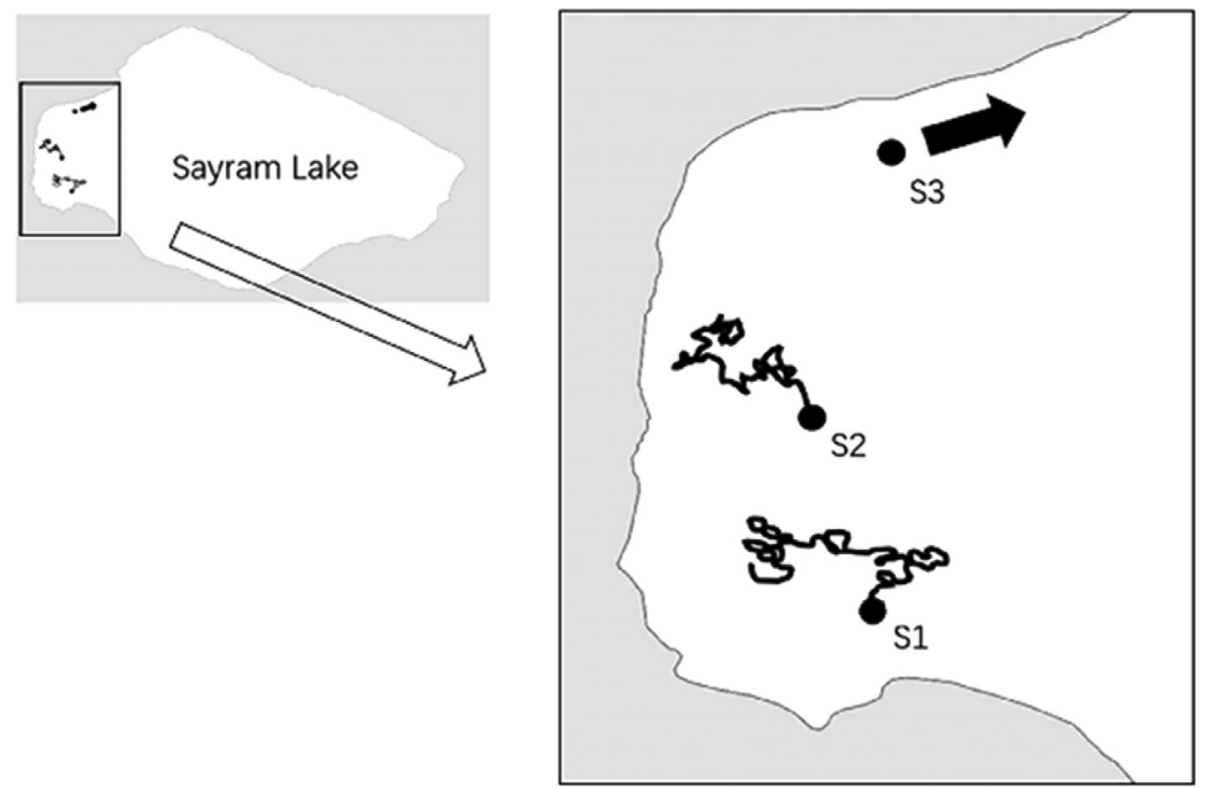

Fig. 7. The result of SBL tracking by boat on the west side of Sayram Lake in 25 July 2017. S1 and S2 are the two release positions of the boat-tracking experiment, and the black thick line is the tracking path of the boat. S3 is the set net position in this experiment, and the black arrow represents the escape direction of the test fish.

experimental fish in the set net may be different from those in open water because the fish were confined to a single area, so the limitation of the set net may have affected the diurnal migration patterns of the experimental fish. We are also considering large-scale tracking studies of peled along the shore of Sayram Lake to obtain more accurate information on vertical movement behavior.

\section{Acknowledgement}

We are grateful to the cooperation of Sayram Fishery Company. This study was funded by the Projects of National Key R\&D Program of China (2019YFD0901303). Thanks also to JCK program of Tokyo University of Marine Science and Technology.

\section{References}

[1] Andrews KS, Tolimieri N, Williams GD, Samhouri JF, Harvey CJ, Levin PS. Comparison of fine-scale acoustic monitoring systems using home range size of a demersal fish. Marine Biol 2011;158(10):2377-87.

[2] Arrhenius F, Benneheij BJ, Rudstam LG, Boisclair D. Can stationary bottom split-beam hydroacoustics be used to measure fish swimming speed in situ? Fish Res 2000;45(1): 31-41.

[3] Binder TR, Farha SA, Thompson HT, Holbrook CM, Bergstedt RA, Riley SC, et al. Fine-scale acoustic telemetry reveals unexpected lake trout, Salvelinus namaycush, spawning habitats in northern Lake Huron, North America. Ecol Freshwater Fish 2018;27(2):594-605.

[4] Block BA, Holbrook CM, Simmons SE, Holland KN, Ault JS, Costa DP, et al. Toward a national animal telemetry network for aquatic observations in the United States. Animal Biotelemet 2016;4(1):6.

[5] Boisclair D. An evaluation of the stereocinematographic method to estimate fish swimming speed. Canad J Fish Aquatic Sci 1992;49(3):523-31.

[6] Dewar H, Prince ED, Musyl MK, Brill RW, Sepulveda C, Luo $\mathrm{J}$, et al. Movements and behaviors of swordfish in the Atlantic and Pacific Oceans examined using pop-up satellite archival tags. Fish Oceanogr 2011;20(3):219-41.

[7] Guo Y, Zhang BP, Zhang RM, Cai LG, Tu EX. Evaluation on the effect of introduction and transplantation of Coregonus peled in Sayram lake (in Chinese) Water Conserv Relat Fish 2003;2003(3):30-2.

[8] Guo Y, Cai LG, Zhang RM, Tu EX, Zhang BP. Age and growth of Coregonus peled in the Sayram Lake (in Chinese) J Dalian Fish Univ 2005;2005(2):100-4.

[9] Hayden TA, Binder TR, Holbrook CM, Vandergoot CS, Fielder DG, Cooke SJ, et al. Spawning site fidelity and apparent annual survival of walleye (Sander vitreus) differ between a Lake Huron and Lake Erie tributary. Ecol Freshwater Fish 2018;27(1):339-49.

[10] Madenjian CP, Hayden TA, Peat TB, Vandergoot CS, Fielder DG, Gorman AM, et al. Temperature regimes, growth, and food consumption for female and male adult walleye in Lake Huron and Lake Erie: a bioenergetics analysis. Canad J Fish Aquatic Sci 2018;75(10): 1573-86.

[11] Mitamura H, Uchida K, Miyamoto Y, Kakihara T, Miyagi A, Kawabata Y, et al. Short-range homing in a site-specific fish: search and directed movements. J Experiment Biol 2012; 215(16):2751-9.

[12] Mitsunaga Y. InteractionBetween fish and FishingGear monitored by Biotelemetr (in Japanese) Fish Eng 2006;43(2): 131-7.

[13] Miyamoto Y, Uchida K, Orii R, Wen Z, Shiode D, Kakihara T. Three-dimensional underwater shape measurement of tuna longline using ultrasonic positioning system and ORBCOMM buoy. Fish Sci 2006;72(1):63-8.

[14] Nomura M. Influence of fish behavior on use and design of setnets. Fish behavior and its use in the capture and culture of fishes. 1980. 446-472. 
[15] Ohta I, Kakuma S. Periodic behavior and residence time of yellowfin and bigeye tuna associated with fish aggregating devices around Okinawa Islands, as identified with automated listening stations. Marine Biol 2005;146(3):581-94.

[16] Park JS. Tracking technology of fish by an ultrasonic biotelemetry system. J Fish Marine Sci Educ 2007;19(3):478-90.

[17] Plew DR, Nikora VI, Larned ST, Sykes JR, Cooper GG. Fish swimming speed variability at constant flow: galaxias maculatus. New Zealand J Marine \& Freshwater Res 2007;41(2): $185-95$.

[18] Riley SC, Binder TR, Tucker TR, Krueger CC. Evidence of repeated long-distance movements by lake charr Salvelinus namaycush in Lake Huron. Environ Biol Fish 2018;101(4): 531-45.

[19] Schaefer KM, Fuller DW. Vertical movements, behavior, and habitat of bigeye tuna (Thunnus obesus) in the equatorial eastern Pacific Ocean, ascertained from archival tag data. Marine Biol 2010;157(12):2625-42.

[20] Smith F. Understanding HPE in the VEMCO positioning system (VPS). Availabe: http://vemco.com/wp-content/ uploads/2013/09/understanding-hpe-vps.pdf; 2013.
[21] Steig TW, Ransom BH, Timko MA. Monitoring the behavior of acoustically tagged chinook and steelhead smolts approaching Rocky Reach Dam on the Columbia River. Waterpower 2001;XII(July):9-11.

[22] Thorstad EB, Økland F, Finstad B. Effects of telemetry transmitters on swimming performance of adult Atlantic salmon. J Fish Biol 2000;57(2):531-5.

[23] Tu EX, Cai LG, Guo Y, Zhang RM, Ma YW, Liu KL. Study on the reproductive biology of coregonus peled in Sayram lake (in Chinese) Chin J Fish 2004;2004(2):26-31.

[24] Uchida K, Ogawa H, Hasegawa K, Miyamoto $Y$, Noro $\mathrm{H}_{\text {, }}$ Wada Y, et al. Monitoring the behavior of young bluefin tuna Thunnus orientalis and yellowtail Seriola quinqueradiata in set nets using ultrasonic biotelemetry. Nippon Suisan Gakkaishi 2018;84(1):14-22.

[25] Wang SJ. Relationship between the formation and evolution of Selimu lake and quaternary paleoglaciation (in Chinese) Xinjiang Geograph 1978;1978(1):47-55. 